\title{
VIABILIDADE ECONÔMICA DA INTEGRAÇÃO DE LIXIVIAÇÃO EM PILHAS DE MINÉRIOS DE BAIXO TEOR A UMA UNIDADE INDUSTRIAL DE MINERAÇÃO DE OURO NO URUGUAI
}

\author{
Andrés Gonzalo Reyes Unda ' \\ Carlos Hugo Reyes Martinez ${ }^{2}$ \\ Vanessa de Freitas Cunha Lins ${ }^{3}$ \\ Sônia Denise Ferreira Rocha ${ }^{3}$
}

\section{Resumo}

Este trabalho foi realizado visando-se obter o custo de investimento necessário (CAPEX) e o custo de operação (OPEX) para uma planta industrial de lixiviação de minérios de ouro de baixo teor para uma indústria cujo processo inclui a lixiviação e adsorção do ouro pelo processo CIL (Carbon in Leaching) na região da llha Cristalina de Rivera no Uruguai (ICR). Os parâmetros de operação do processo adotados foram baseados em ensaios segundo a técnica "rolling bottles" em frascos de 20 litros e colunas de 3 metros. Foram definidos os critérios de operação e dimensionamento para uma planta de lixiviação em pilhas dinâmicas para 1.000 .000 de toneladas de minério de ouro de baixo teor $(0,65 \mathrm{~g} / \mathrm{t}) \mathrm{com}$ granulometria proposta de $12,7 \mathrm{~mm}$. Para a análise de viabilidade considerou-se a existência das linhas de produção já existentes de adsorção, dessorção e fundição que poderá contribuir com um incremento na produção anual de ouro de até $24 \%$. O projeto apresenta viabilidade econômica com um Valor Presente Liquido (VPL) de 8.649.276 US\$, uma Taxa Interna de Retorno (TIR) de 3I,21\% e payback descontado de 2, 10 anos operando durante 3 anos.

Palavras-chave: Ouro; Minério de baixo teor; Lixiviação em pilhas; Viabilidade econômica.

\section{ECONOMIC FEASIBILITY OF INTEGRATION OF HEAP LEACHING OF LOW GRADE ORES TO AN INDUSTRIAL UNIT OF GOLD MINING IN URUGUAY}

\begin{abstract}
This work aimed at obtaining the necessary investment cost (CAPEX) and operating costs (OPEX) for an industrial heap leaching plant of low grade gold ores for an industry that currently leaches and adsorbs gold by the process CIL (Carbon in Leaching) in the region of Rivera Crystalline Island (ICR), Uruguay. The adopted process parameters were estimated from tests on rolling bottles of 20 liters and columns of 3 meters high, establishing operating criteria and design for a dynamic heap leaching plant of I, 000,000 tons of low-grade gold ore $(0.65 \mathrm{~g} / \mathrm{t})$ with a proposed granulometry of $12.7 \mathrm{~mm}$ using the preexisting production lines of adsorption, desorption and smelting, contributing to an increase in annual gold production up to $24 \%$. The project also presents economic feasibility with a Net Present Value (NPV) of US\$ 8.649.276, an Internal Rate Return (IRR) of 31.21\% and discounted Payback of 2.10 years operating for 3 years.
\end{abstract}

Keywords: Gold; Low grade ores; Heap leaching; Economic viability.

\section{INTRODUÇÃO}

A planta industrial de produção de ouro, localizada no norte do Uruguai na região da llha Cristalina de Rivera (ICR), utiliza as operações de lixiviação e adsorção utilizando tanques com agitação pelo processo Carbon in Leaching (CIL), tendo sido projetada para processar minérios de ouro de alto teor e para operar durante 7 anos. Entretanto, a planta opera há mais de 17 anos, isso devido à qualidade das explotações e novas minas encontradas durante a vida útil da planta.

Durante as explotações, foram encontrados minérios de baixo teor contendo em média $0,65 \mathrm{~g} / \mathrm{t}$ de ouro, além dos

'Programa de Pós-graduação em Engenharia Química, Universidade Federal de Minas Gerais - UFMG, Belo Horizonte, MG, Brasil.

${ }^{2}$ C. Reyes Consultores Hidrometalúrgicos, Santiago, Chile.

${ }^{3}$ Departamento de Engenharia Química, Escola de Engenharia, Universidade Federal de Minas Gerais - UFMG, Belo Horizonte, MG, Brasil.

E-mail:vlins@deq.ufmg.br

2176-1523/C 2016 Associação Brasileira de Metalurgia, Materiais e Mineração. Publicado pela ABM. Este é um artigo de acesso aberto distribuído sob os termos da licença Creative Commons CC BY-NC-ND (Attribution-NonCommercial-NoDerivs) distribuído sob os termos da licença Creative Comm
https://creativecommons.org/licenses/by-nc-nd/4.0/. 
minérios de alto teor de ouro. Assim, foi necessário verificar uma alternativa econômica para a recuperação deste ouro aproveitando-se o circuito de adsorção, dessorção e fundição já existente na planta atual. Como parte do desenvolvimento e pesquisa, foi avaliada uma rota alternativa ao processo CIL para minérios de ouro de baixo teor, para processar I.000.000 de toneladas por ano de minério já extraído, sendo que uma das opções estudadas para a extração de ouro seria a lixiviação em pilhas.

A definição dos parâmetros ótimos de processo é importante, pois pode reduzir os custos de investimento e operação $[1,2]$. A granulometria adequada depende do tipo de minério, mas a faixa ótima encontrada foi entre $1 / 4$ " $(6,35 \mathrm{~mm})$ e $3 / 4 "(19 \mathrm{~mm})$ [3-6]. Cabe ressaltar também que a operação unitária de redução de tamanho do minério e a etapa de aglomeração para a formação das pilhas de lixiviação podem gerar custos adicionais e/ou inviabilizar o processo, caso não tenham um controle adequado [7]. No caso da redução de tamanho, os custos podem representar até $18 \%$ dos custos de operação de uma planta de lixiviação [7].

$\mathrm{Na}$ Tabela I, estão indicados alguns parâmetros operacionais de plantas de lixiviação em pilhas de ouro de minérios de baixo teor segundo Manrique [3] para pilhas de lixiviação da planta industrial Yanacocha, localizada em Lima, Peru.

Considerando-se que, para a viabilidade de uma nova planta industrial, é necessário levar em conta os custos de instalação e operação, foram verificados quais seriam os custos estimados para projetos dessa natureza, seja considerando-se projetos já em operação ou projetos realizados anteriormente.

Segundo Ortiz [8], os custos de instalação de uma planta de lixiviação em pilhas correspondem a $20-30 \%$ de uma planta de lixiviação por agitação; já os custos de operação flutuam entre $30 \%$ e $65 \%$, comparando-se os mesmos processos. Dados de 2001 mostram plantas de lixiviação em pilhas no estado de Nevada, Estados Unidos, que operavam com custos da ordem de US $\$ 1,70$ a US $\$ 5,32$ por tonelada processada, e custos de US\$7,0 por tonelada processada para uma planta no Peru [8]. Os custos de processamento e administrativos para lixiviação de minérios de ouro em 2013 atingiram valores da ordem de US $\$ 12,15$ por grama de ouro (US\$/t 7,89 de minério) [9]. Em Nevada, Estados Unidos, uma planta que processava I.000.000 t/ano de minério de ouro de baixo teor durante o período de 4,4 anos com recuperações de ouro de $86 \%$ e prata de $15 \%$ estimou um CAPEX de US\$25.357.000, um OPEX de US $\$ 3,65$ para a lixiviação de minério, OPEX global de US $\$ 14,87$ e uma contingência de $10 \%$ [10].

Ressalta-se que os custos com o reagente cianeto de sódio giram em torno de $31 \%$ dos custos totais de uma planta de lixiviação de ouro de baixo teor [I I].

Para estimativa dos custos envolvidos em equipamentos elétricos e mecânicos foram realizados orçamentos com provedores em Santiago do Chile: Haver \& Boecker, Cemin, Sandvik, Trio e Metso. Também por questões relacionadas a câmbio, pesos chilenos e dólar americano, valores de mercado de ouro e prata foram tomados no dia 26 de maio de 2014 como referência e os valores foram extraídos da base de dados estatísticos do Banco Central do Chile [12].

A partir dos resultados obtidos para os testes piloto em recipientes giratórios de 20 litros e colunas de 3 metros de altura, foi possível estimar os custos de instalação e operação para a planta de lixiviação em pilhas dinâmicas de 3 a 4 metros de altura operando no Uruguai para o processamento de I.000.000 de toneladas por ano de minério de baixo teor $(0,65 \mathrm{~g} / \mathrm{t})$ com recuperações de ouro da ordem de $70 \%$, operando por três anos. Alguns dos parâmetros adotados para a planta industrial são apresentados na Tabela 2. O parâmetro $\mathrm{F}_{100}$ representa a granulometria na qual $100 \%$ do material possui granulometria menor que $800 \mathrm{~mm}$, P80 representa a granulometria em que $80 \%$ do material possui granulometria menor que P80 (12,7 mm).

Tabela I. Parâmetros de lixiviação em pilhas da planta industrial de Yanacocha em Lima, Peru [3]

\begin{tabular}{ccccc}
\hline Identificação & $\begin{array}{c}\text { Período } \\
\text { (Dias) }\end{array}$ & $\begin{array}{c}\text { Adição de Cal } \\
\mathbf{( K g / t )}\end{array}$ & $\begin{array}{c}\text { Dosificação da solução } \\
\left(\mathbf{L} /\left(\mathbf{h} . \mathbf{m}^{2}\right)\right)\end{array}$ & $\begin{array}{c}\text { Recuperação de Au } \\
\mathbf{( \% )}\end{array}$ \\
\hline Maqui-Maqui & 45 & 0,55 & 8,0 & 82,4 \\
Carachugo & 60 & 0,75 & 10,0 & 85,0 \\
Yanacocha & 60 & 0,75 & 10,0 & 74,7 \\
La Quinua & 75 & 0,75 & 10,0 & 76,7 \\
\hline
\end{tabular}

Tabela 2. Parâmetros para lixiviação em pilhas de minérios de ouro de baixo teor

\begin{tabular}{cccc}
\hline Item & Parâmetro & Item & Parâmetro \\
\hline $\mathrm{F}_{100}-$ Minério & $800 \mathrm{~mm}$ & Razão de aplicação da solução & $10 \mathrm{~L} /\left(\mathrm{h} . \mathrm{m}^{2}\right)$ \\
Índice de trabalho & $22 \mathrm{kWh} / \mathrm{t}$ & Concentração de cianeto & $1000 \mathrm{ppm}$ \\
Teor de Ag & $2,0 \mathrm{~g} \mathrm{Ag} / \mathrm{t}$ & Adição de cal & $1,9 \mathrm{~kg} \mathrm{Cal} / \mathrm{t}$ \\
Recuperação de Prata & $50 \%$ & $\mathrm{pH}$ & $>10,5$ \\
$\mathrm{P}_{80}$ lixiviação & $12,7 \mathrm{~mm}$ & Duração do ciclo & 45 dias \\
\hline
\end{tabular}


A nova planta poderia trazer um incremento de produção de $455 \mathrm{~kg}$ de ouro o que corresponde a $24,3 \%$ da produção de 2014 , que foi de $1.874,64 \mathrm{Kg}$. Portanto, o objetivo desse trabalho é avaliar a viabilidade econômica de uma rota alternativa de produção de ouro utilizando pilhas de lixiviação para minérios de diversas minas disponíveis, buscando condições ótimas de implantação e operação.

\section{MATERIAIS E MÉTODOS}

Foram estimados os custos de investimento e operação necessários para operar uma planta de processo com I.000.000 toneladas de minério de ouro de baixo teor $(0,65 \mathrm{~g} / \mathrm{t})$ durante o período de três anos. Os custos associados ao investimento contemplaram a aquisição, construção e início de operação de uma nova planta de processo. Todo o sistema atual de mina, adsorção, dessorção e fundição foram reaproveitados utilizando-se o sistema atual de tanques agitados, CIL. As demais áreas necessárias para implantação da nova planta industrial foram divididas em: área de secos composta por britagem primaria, britagem secundária e terciária, silo de finos e aglomeração e área úmida composta por: lixiviação em pilhas e movimentação de reagentes, área de serviços, gastos em geral e, por último, a parte administrativa da planta industrial.

O projeto utilizou uma disponibilidade de $75 \%$ para equipamento de processamento de minérios e movimentação de rejeitos e de $96 \%$ para equipamentos de processamento de soluções líquidas. A estimativa de custos levou em conta dados fornecidos pela empresa, dados padrões da indústria, recomendações de consultores, recomendações de fornecedores, informações de manuais de engenharia, cálculo de processo e de ensaios metalúrgicos realizados nos testes de lixiviação em colunas.

\section{I Descrição das Instalações}

A nova planta industrial é composta de duas grandes áreas: área de fragmentação e aglomeração, área seca e área úmida. A Figura I indica uma proposta de fluxograma da área seca composta por britagem primária, secundária e terciária.

A área de britagem primária recebe o minério descarregado em um alimentador (I) com capacidade de 100 toneladas, seguindo a um alimentador vibratório (2) responsável pela segregação, o material grosso é enviado para o britador tipo mandíbulas (3) de $1000 \times 900 \mathrm{~mm}$ que reduz em 4,5 vezes a granulometria deste e, posteriormente, a um receptor de material (4) seguindo para a correia principal (5) incorporando o material passante em (2) formando a pilha pulmão de minério grosso (6), sendo a capacidade de $10.000 \mathrm{t}$.

A britagem secundária recebe o material (6) a partir das correias (7) e (8). O material fino e grosso é dosado e enviado para a correia principal (9) e direcionado para o alimentador vibratório (I0) que separa os finos (I2), que são enviados para o silo de finos pela correia (20), e o material grosseiro segue para o britador secundário tipo cônico de cabeça padrão (I I). A granulometria do material grosseiro é reduzida em até 5,6 vezes e o material segue a um receptor de material (I3), capacidade $282 \mathrm{t}$, que o distribui em duas calhas vibratórias (14 e I5) e dois britadores terciários (18 e 19), com capacidade de reduzir em até 2,5 vezes a granulometria, com carga circulante (2I) que retorna ao alimentador vibratório (I0). Os finos

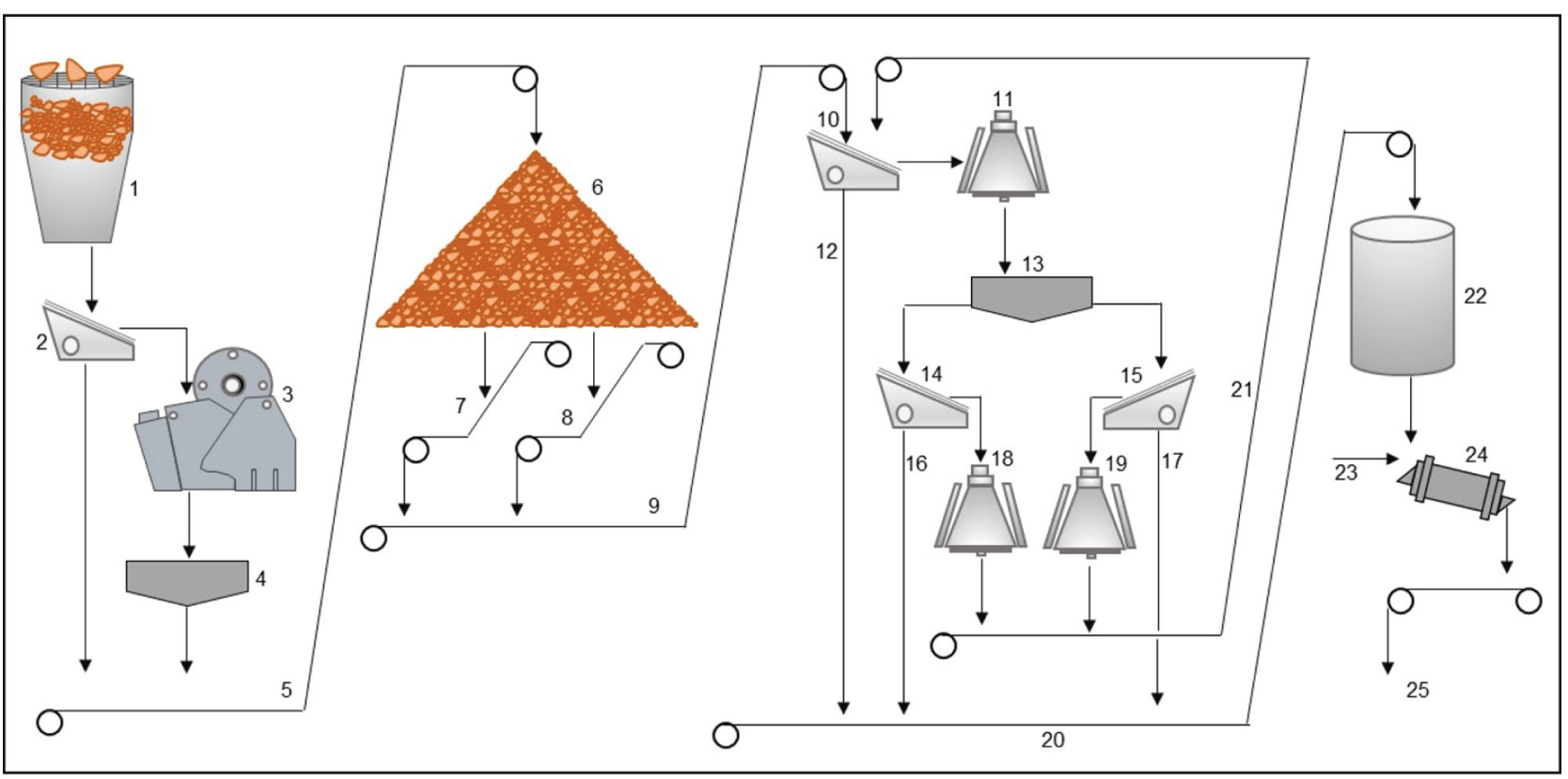

Figura I. Esquema básico da área de secos: britagem e aglomeração. 
$(12,16$ e I7) alimentam a correia (2I), que abastece o silo de finos (22) com capacidade de $300 \mathrm{t}$.

A área de aglomeração (24) recebe finos (22) com minério na granulometria de trabalho para, então, preparar o material aglomerado que também recebe água e cal (23) para então disponibilizar o minério aglomerado (25) para enviar para a preparação das pilhas de lixiviação na área úmida.

A área úmida se inicia com o minério aglomerado e na granulometria de trabalho. Este alimenta uma correia transportadora que transporta o material para uma correia com ponte distribuidora, sistema móvel, para realizar a formação das pilhas, de acordo com o plano de carga. O transporte de material para a formação das pilhas pode também ser realizado usando-se caminhões, situação a ser avaliada em outra etapa do projeto. O fluxograma das pilhas de lixiviação e o circuito de líquido são apresentados na Figura 2.

O minério fino aglomerado é utilizado para a formação da pilha dinâmica de lixiviação (I) com base de $300 \mathrm{~m} \times 100 \mathrm{~m}$, incluindo taludes e canaletas perimetrais. A base das pilhas é compactada e possui uma pequena inclinação de $0,3 \%$ (cerca de 0,2 graus por metro linear) na direção transversal e I,5\% (cerca de 0,95 graus por metro linear) na direção longitudinal, para deslocamento da solução rica e posterior bombeamento desta para as próximas etapas. As camadas que formam a base são: uma capa (2A) de $0,3 \mathrm{~m}$ de material arenoso (condutividade hidráulica $1 \times 10^{-6} \mathrm{~cm} / \mathrm{s}$ ) e impermeabilizado com uma manta lisa (2B) de material impermeável, de polietileno de alta densidade (HDPE) de I,5 mm de espessura, sobre a qual se adiciona um material para a drenagem (2C), também denominado "heel" ou "cover", de 0,4 m que permitirá a drenagem, por tubulações transversais, instaladas a cada 4 metros, da solução rica e que, portanto, protegerá a lamina de HDPE. A parte inferior de cada pilha será conformada com um material fino coberto com uma película de HDPE ( $1,5 \mathrm{~mm})$ formando canaletas para recolher as soluções de cada módulo.

A solução rica denominada "Pregnant Leach Solution" ou PLS (3) é enviada a um tanque de decantação (4), para sedimentação de sólidos, e, em seguida, para a piscina de PLS (6). O fluxo do PLS normalmente é para a planta de processo (7), para a extração de ouro ou para a piscina de emergência (15), em casos especiais. Após realizar a extração de ouro, a solução de processo retorna para o circuito de lixiviação $(10)$ e é direcionada para a piscina de solução pobre denominada "Barren Leach Solution" (8), na qual realiza-se o controle de concentração de $\mathrm{NaCN}$ pela adição da linha de $\mathrm{NaCN}$ (9), conforme concentração de trabalho, ou pela adição de solução de processo, linha (14), da piscina de emergência. Por último, a solução de alimentação (II) está apta para realizar o processo de lixiviação na pilha de minério.

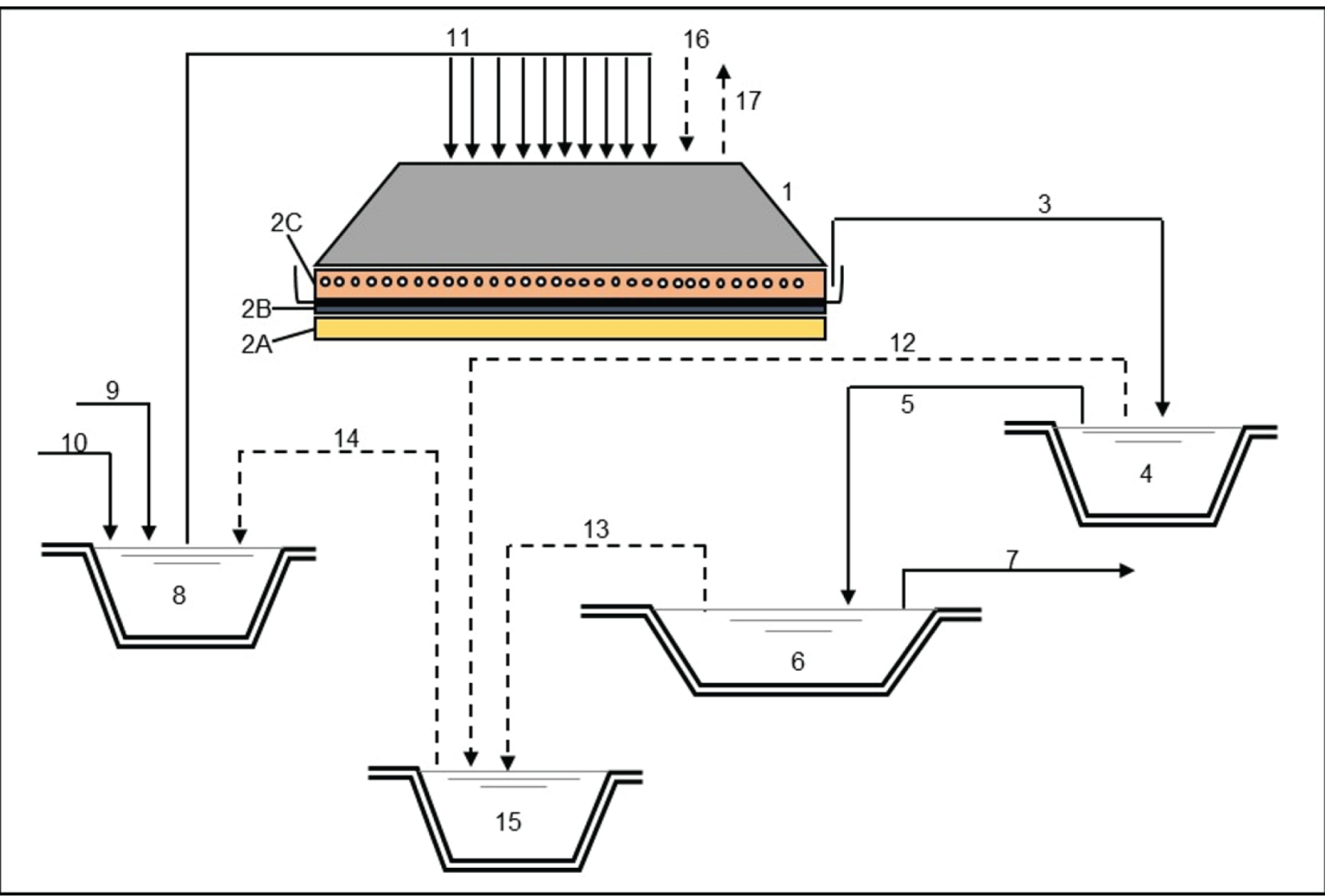

Figura 2. Esquema básico da área úmida com a lixiviação em pilhas. 
As piscinas de PLS (6) e solução pobre (8) foram construídas em forma de tronco de pirâmide invertida revestida com HDPE e com uma película secundaria lisa de I mm de espessura, além de uma película intermediaria de geomalha de HDPE de $5 \mathrm{~mm}$ de espessura e, por último, de uma película de revestimento primário de $1,5 \mathrm{~mm}$ de espessura. Estas piscinas poderão contar também com uma cobertura flutuante de HDPE. Já a piscina de emergência é formada por uma lâmina de revestimento de HDPE de $2 \mathrm{~mm}$ de espessura. As linhas pontilhadas ( 12,13 e I4) são fluxos eventuais e ocorrerão por medida de segurança ou alternativa de processo, enquanto que as linhas 16 e 17 correspondem, respectivamente, à precipitação de chuvas e evaporação de água das pilhas, que dependerão das condições naturais da região.

\subsection{Custos de investimento - CAPEX}

Para a composição do CAPEX foi considerado o dólar americano com valor de 553,95 \$ /US\$. Para a obra civil, foram considerados a experiência da equipe de trabalho e critérios padrões, para escavações estruturais foram consideradas as fundações e os equipamentos que o necessitem, também considerando um talude com segurança adequada. Para se estimar o custo das tubulações, utilizou-se a estimativa de $20 \%$ dos custos dos equipamentos mecânicos, para os equipamentos elétricos, cabos elétricos e canalizações considerou-se o valor de $14 \%$ dos custos dos equipamentos mecânicos enquanto que para a estimativa dos custos com instrumentação e controle, considerou-se $\circ$ montante de $10 \%$ dos custos de equipamentos mecânicos. Foram feitos orçamentos no mercado chileno para os principais equipamentos mecânicos, elétricos, válvulas e instrumentação. Para os custos de mão de obra foram considerados o salário base, fundos de aposentadoria, plano de saúde, férias, indenizações e planos de segurança.

\subsection{Custos de operação - OPEX}

Para a composição dos custos de operação foram considerados: mão de obra para administração, operação e manutenção da planta de processo, insumos, reagentes, energia e materiais de operação, materiais de manutenção, serviços externos e contingência operacional. Para a mão de obra considerou-se toda a utilização atual para a planta industrial existente e as atividades que necessitariam de mão de obra adicional considerando-se os valores pagos de homem-hora atuais pela empresa. Já os custos dos insumos (energia, águas e reagentes) e materiais de operação foram estimados a partir dos consumos unitários atuais da planta industrial. $\mathrm{O}$ consumo médio de energia foi estimado com base nos equipamentos que comporiam a nova planta de processo com uma taxa de operação de 2.740 toneladas por dia. O consumo de água foi avaliado a partir do balanço de massa para a nova planta e considerando o fator de consumo humano de 200 litros por dia por pessoa. Finalmente, os materiais de manutenção e reposição foram estimados em $3 \%$ do custo de aquisição dos equipamentos principais.

\section{RESULTADOS E DISCUSSÃO}

Os custos de investimento, custos de operação e valores monetários são indicados nas Tabelas 3, 4 e 5, respectivamente, e são discutidos a seguir.

O total de custos de investimentos é de 20.409.784 US\$ para o qual adotou-se uma contingência de $15 \%$, totalizando um custo de 23.47I.25 I US\$, custo este similar ao apresentado em Nye Conty, Nevada USA [10].

Tabela 3. Custos de instalação para a planta de lixiviação em pilhas

\begin{tabular}{|c|c|c|c|}
\hline \multicolumn{2}{|c|}{ Custos Diretos } & \multicolumn{2}{|l|}{ Custos Indiretos } \\
\hline Item & Valor (US\$) & Item & Valor (US\$) \\
\hline Terraplanagem & 5.563 .639 & Prédios & 136.699 \\
\hline Obras civis & 613.658 & Fretes, Seguro de equipamentos e materiais & 437.035 \\
\hline Estrutura Metálica & 2.147 .676 & Nacionalização de equipamentos & 111.763 \\
\hline Concreto & I.442.40 I & Materiais de reposição importados & 219.902 \\
\hline Tubulações & 239.113 & Representante técnico - & 153.932 \\
\hline Bombas & 178.533 & Rump up & 715.000 \\
\hline Equipamentos mecânicos & 3.813 .182 & Factibilidade & 350.000 \\
\hline Equipamentos elétricos & 1.448 .876 & & \\
\hline Instrumentação e controle & 319.630 & Engenharia e gerenciamento da construção & 1.654 .000 \\
\hline Cabeamento de energia & 455.765 & Comissionamento da planta & 408.979 \\
\hline Total Custos Diretos & 16.359 .172 & Total Custos Indiretos & $4.050 .6 \mathrm{II}$ \\
\hline \multicolumn{2}{|c|}{ TOTAL (SEM CONTINGENCIA) } & \multicolumn{2}{|l|}{ 20.409.784 US\$ } \\
\hline \multicolumn{2}{|c|}{ CONTINGENCIA I5\% } & \multicolumn{2}{|l|}{3.061 .467 US\$ } \\
\hline \multicolumn{2}{|c|}{ CUSTO TOTAL } & \multicolumn{2}{|l|}{23.471 .25 I US\$ } \\
\hline
\end{tabular}


Tabela 4. Custos de operação da planta industrial de lixiviação em pilhas

\begin{tabular}{|c|c|c|c|c|}
\hline \multicolumn{2}{|l|}{ Item } & Valor (US\$) & Item & \multirow{2}{*}{$\begin{array}{c}\text { Valor (US\$) } \\
5303200\end{array}$} \\
\hline Mão de Obra & & 3.569 .664 & Reagentes & \\
\hline Energia & & I.84I.279 & Materiais de reposição e manutenção & 482800 \\
\hline Materiais de Operação & & 172.002 & Gastos gerais e serviços & 768064 \\
\hline Água industrial e potável & & 2.146 & Outros Custos & 606958 \\
\hline & TOTAL & & \multicolumn{2}{|c|}{ I2.746.II3 US\$ } \\
\hline & TOTAL & & \multicolumn{2}{|c|}{6,37 US\$ / t } \\
\hline & TOTAL & & \multicolumn{2}{|c|}{422 US\$ / Oz Au Eq. } \\
\hline & TOTAL & & \multicolumn{2}{|c|}{ I4 US\$ / g Au Eq. } \\
\hline
\end{tabular}

Tabela 5. Valores monetários da planta industrial de lixiviação em pilhas

\begin{tabular}{cccc}
\hline Item & Valor & Item & Valor \\
\hline Capex & $23.47 I .25$ I US\$ & Entrada anual & 19.5 I7.196 US\$ \\
Opex & 6.373 .056 US\$ & Fluxo de Caixa anual & 13.144 .140 US\$ \\
Taxa de desconto anual & $11 \%$ & VPL (taxa II\%) & $8.649 .276,39$ US\$ \\
TIR & $31,21 \%$ & Payback simples & 1,79 anos \\
Payback descontado (8\%) & 2,10 anos & & \\
\hline
\end{tabular}

Tabela 6. Valores monetários da planta industrial considerando a cotação de venda do ouro de 1078 US\$/oz

\begin{tabular}{cccc}
\hline Item & Valor & Item & Valor \\
\hline Capex & 23.471 .25 I US\$ & Entrada anual & 16.393 .992 US\$ \\
Opex & 6.373 .056 US\$ & Fluxo de Caixa anual & 10.020 .935 US\$ \\
Taxa de desconto anual & $11 \%$ & VPL (taxa II\%) & 1.017 .057 US\$ \\
TIR & $13,48 \%$ & Payback simples & 2,34 anos \\
Payback descontado (I \%) & 2,86 anos & & \\
\hline
\end{tabular}

Já para os custos de operação, indicados na Tabela 4, foram assumidos os valores de mercado para ouro e prata, US\$ 4I,52 por grama (US\$I 29I,50/Oz) para o ouro e de US $\$ 0,62$ por grama (US\$ $19,42 / \mathrm{Oz}$ ) para a prata, usando-se a cotação de 26 de maio de 2014 [12] enquanto que o preço do cianeto de sódio considerado foi de 2.600 US\$ por tonelada. Também foi considerado um adicional de 40 empregados para a nova planta, sendo que algumas atividades seriam realizadas em conjunto com empregados da planta existente. Os custos de operação são indicados na Tabela 4.

O custo de operação em média seria de US\$ 6,37 por tonelada de minério processada, similar ao custo relatado por Ortiz [8] e Cochilco [9]. O gasto médio anual seria de US\$ 6.373.056 por ano considerando o processamento de I.000.000 de toneladas de minério. $O$ maior aporte para os custos corresponde ao consumo de reagentes, que representa aproximadamente $41,60 \%$, sendo que $68,63 \%$ destes correspondem ao cianeto de sódio. Portanto, 0 cianeto de sódio representa aproximadamente $28,56 \%$ dos custos totais de operação, porcentagem essa similar à reportada por Manrique [3]. Considerando os valores de Capex e Opex para esta planta industrial de lixiviação em pilhas e, ainda considerando a taxa de desconto anual de II\%, no período de 3 de abril de 2014 a 28 de maio de 2015, conforme Banco Central do Brasil [13], os valores do Valor Presente Líquido (VPL), Taxa Interna de Retorno, TIR, e payback foram calculados e são apresentados na Tabela 5 .

Considerando que o VPL é positivo, que a TIR é superior à taxa praticada e que o payback descontado é de 2, 10 anos ( 2 anos, I mês e seis dias) o investimento e operação da planta de lixiviação em pilhas do ponto de vista econômico é um bom investimento e também poderia vir a incrementar a oferta de trabalho para a região além de prolongar a vida útil da planta industrial existente. Também se verificou qual a sensibilidade do projeto em relação à variação do preço de venda do ouro. Considerando-se o histórico de janeiro de $20 \mathrm{II}$ a agosto de 2015, o menor valor de venda do ouro foi de 34,6585 US\$/g ( 1.078 US\$/oz) em julho de 2015 [ 12$]$. Os valores econômicos estão indicados na Tabela 6.

Ainda assim seria um bom investimento considerando que $\circ \mathrm{VPL}$ é positivo, que a taxa TIR é superior à taxa praticada e que o payback descontado é de 2,86 anos ( 2 anos, 10 meses e 10 dias). 


\section{CONCLUSÃO}

Um estoque de 3.000 .000 toneladas de minério de baixo teor de ouro, com 0,65 g/t, seria suficiente para viabilizar uma planta de lixiviação em pilhas operando durante 3 anos. O VPL e a TIR deste projeto indicam condições favoráveis à implantação do mesmo, além de um payback descontado de 2, 10 anos.

A extração de minério de ouro de baixo teor é viável, pois com a planta em operação aumentaria os ganhos de capital uma vez que o CAPEX já estaria pago.
As taxas de alimentação de solução de cianeto poderiam ser iniciadas com o valor de $\mathrm{l} \mathrm{L} / \mathrm{h} / \mathrm{m}^{2}$ e, posteriormente, sofrer redução, avaliando-se a extração de ouro, com isso poderia reduzir o consumo e custo do cianeto, que é responsável por $28,56 \%$ do Opex aumentando assim os lucros da empresa.

A planta industrial apresenta valores de VPL de 8.649.276 US\$, TIR de 3I,2I\% e payback descontado de 2, 10 anos, favoráveis à construção da planta industrial de lixiviação em pilhas de minérios de ouro de baixo teor incorporada ao processo atual CIL.

\section{REFERÊNCIAS}

I Roenick FSF. Extração de ouro contido em minério de baixo teor empregando pilhas de lixiviação com cianeto [dissertação de mestrado]. Belo Horizonte: Escola de Engenharia, Universidade Federal de Minas Gerais; 2013.

2 Villas Bôas RC, Lima LRPA, Kohler HM. Modelagem e simulação do processo de lixiviação em pilhas de minérios auríferos voltados ao desenvolvimento de critérios de sustentabilidade. In: Villas Bôas RC, Beinhoff C. Indicadores de sostenibilidad para la industria extractiva mineral. Rio de Janeiro: CNPq/CYTED; 2002. p. 24I-26I.

3 Manrique MJA. Manejo de pilas de lixiviación de oro en minera Yanacocha S.R.L. [tese de doutorado]. Lima: Universidad Mayor de San Marcos; 2005.

4 Payano JT. Caracterización, influencia y tratamiento de arcillas en procesos de cianuración en pila [tese de doutorado]. Oviedo: Universidad de Oviedo; $201 \mathrm{I}$.

5 Guilbert JM, Park CF. The geology of ore deposits. Oxford: The Freeman; 1986. p. 983-985.

6 Murr LE, Schlitt W], Cathles LM. Experimental observations of solution flow in the leaching of copper-bearing waste. In: Schlitt WJ, Hiskey JB. Interfacing technologies in solution mining. Proceedings of the 2nd SME-SPE International Solution Mining Symposium; 198I; Denver, CO. New York: American Institute of Mining, Metallurgical and Petroleum Engineers; 1982. p. 27I-290.

7 Murr LE. Theory and practice of copper sulphide leaching in dumps and in situ. Minerals Science and Engineering. 1980;12:121-189.

8 Ortiz AA. Recuperación de oro y plata de minerales por Heap Leaching. Revista del instituto de investigación de la Faculdad de Geología, Minas, Metalurgia y Ciencias Geograficas. 200।;4:8-9.

9 Comisión Chilena del Cobre - Cochilco. Gobierno de Chile. Ministerio de Minería. Metales preciosos: mercado del oro y plata. Chile: Cochilco; 2014. p. 4-16.

10 Star Gold Inc. Scoping Study Longstreet Gold Project [página da internet]. Nye Conty: Star Gold; 2014 [acesso em 30 jan. 2015]. Disponível em: http://stargoldcorp.com/presentation/LongstreetScopingStudyMay20 I4.pdf

I I Dhawan N, Safarzadeh MS, Miller JD, Moats MS, Rajamani RK. Crushed ore agglomeration and its control for heap leach operations. Minerals Engineering. 2013;41:53-70. http://dx.doi.org//0.1016/j.mineng.2012.08.013.

12 Banco Central de Chile. Base de datos estadísticos: indicadores diários [página da internet]. Santiago: Banco Central; 2014 [acesso em 27 maio 20l4]. Disponível em: http://si3.bcentral.cl/Indicadoressiete/secure/Indicadoresdiarios. aspx

13 Banco Central do Brasil. Histórico das taxas de juros [página da internet]. Brasília: Banco Central; 2015 [acesso em 22 jan. 2015]. Disponível em: http://www.bcb.gov.br/?COPOMJUROS

Recebido em: 10 Out. 2015

Aceito em: 04 Mar. 2016 